\title{
GCU
}

Glasgow Caledonian

University

University for the Common Good

\section{Effect of GGBS on water absorption capacity and stability of superabsorbent polymers partially crosslinked with alkalis}

Almeida, Fernando C.R. ; Klemm, Agnieszka J.

Published in:

Journal of Materials in Civil Engineering

DOI:

10.1061/(ASCE)MT.1943-5533.0002511

Publication date:

2018

Document Version

Author accepted manuscript

Link to publication in ResearchOnline

Citation for published version (Harvard):

Almeida, FCR \& Klemm, AJ 2018, 'Effect of GGBS on water absorption capacity and stability of superabsorbent polymers partially crosslinked with alkalis', Journal of Materials in Civil Engineering, vol. 30, no. 12, 2511.

https://doi.org/10.1061/(ASCE)MT.1943-5533.0002511

\section{General rights}

Copyright and moral rights for the publications made accessible in the public portal are retained by the authors and/or other copyright owners and it is a condition of accessing publications that users recognise and abide by the legal requirements associated with these rights.

Take down policy

If you believe that this document breaches copyright please view our takedown policy at https://edshare.gcu.ac.uk/id/eprint/5179 for details

of how to contact us. 
1 Effect of GGBS on water absorption capacity and stability of superabsorbent polymers

\section{2 partially crosslinked with alkalis}

3

4 Fernando C.R. Almeida ${ }^{1}$, Agnieszka J. Klemm ${ }^{2}$

5

$6{ }^{1} \mathrm{PhD}$ Student, School of Engineering and Built Environment, Glasgow Caledonian University, 7 Cowcaddens Road, Glasgow, G4 0BA, United Kingdom. BSc (Eng), MSc. E-mail: $8 \quad$ fernando.almeida@gcu.ac.uk (Corresponding author)

$9{ }^{2}$ Full Professor, School of Engineering and Built Environment, Glasgow Caledonian University, 10 Cowcaddens Road, Glasgow, G4 0BA, United Kingdom. PhD, MSc (Eng), FICT, ICIOB, FHEA. $11 \quad$ E-mail: a.klemm@gcu.ac.uk

Abstract

In an attempt to improve sustainability of construction and reduce Portland cement (PC) consumption, supplementary cementitious materials (SCM), such as ground granulated blast furnace slag (GGBS), has become a common practice. On the other hand, in order to increase durability of cementitious composites, various internal curing agents, including superabsorbent polymers (SAP), are often implemented. Due to their high capacity to absorb, retain and release water SAPs can provide additional water for continuous hydration and lead to more homogenous microstructures. They are usually neutralized by alkali metals (sodium and potassium) to increase their absorption capacities and keep them stable in PC cementitious matrices. This paper discusses the applicability of SAPs in blended systems. It aims to evaluate the effect of GGBS on water absorption capacity and stability of three partially neutralized SAPs. SAPs swelling capacity and kinetics of the absorption, $\mathrm{pH}$ of binder solutions over time, as well as mechanical properties of PC-GGBS matrices have been analysed. The results showed that alkalis content up to $4 \mathrm{wt} \%$ lead to a GGBS system comparable to a stable PC system. Above this limit, degradation of SAP starts to take place due to ion-exchange with GGBS solution components, resulting in lower compressive strength when compared to PC matrices. Thus, the excess of alkalis in SAPs network plays an important role in GGBS aqueous solution.

Keywords: Superabsorbent polymers (SAP), ground granulated blast-furnace slag (GGBS), absorption capacity, alkalinity, cementitious materials 
Construction industry is constantly searching for innovations and sustainable solutions to enhance environmental, structural and cost requirements. The massive production of ordinary Portland cement (PC), the main cementitious material, requires consumption of high energy levels and large amounts of non-renewable raw-materials. It is estimated that $5-6 \%$ of all $\mathrm{CO}_{2}$ emissions generated by human activities is derived from cement manufacture (Damineli et al. 2010; Fairbairn et al. 2010; Flower and Sanjayan 2007; Huang et al. 2018; John and Zordan 2001; Pacheco-Torgal et al. 2013; Rodrigues and Joekes 2011; Scrivener et al. 2016). In an attempt to mitigate this environmental issue, the use of supplementary cementitious materials, such as ground granulated blast-furnace slag (GGBS), has become a common construction practice (Almeida and Klemm 2018; Hooton 2008; Li 2016; Lothenbach et al. 2011; Sales and Lima 2010; Siddique 2014). This by-product from pig iron manufacture is a latent hydraulic material that can replace $\mathrm{PC}$ in contents up to $85 \%$ by weight (Siddique 2014; Siddique and Bennacer 2012). However, higher GGBS contents may have serious implications on concrete durability. On one hand, it can reduce permeability and increase resistance to deleterious processes (e.g. chloride penetration, alkali-silica reaction and sulphate attack) (Almeida et al. 2015; Divsholi et al. 2014; Klemczak and Batog 2016; Krivenko et al. 2014; Loser et al. 2010; Moretti et al. 2018; Thomas 2011). On the other hand, GGBS may lead to increased carbonation rate, decreased resistance to freezing/thawing and volumetric instability (Bouasker et al. 2014; Divsholi et al. 2014; Ghourchian et al. 2018; Lee et al. 2006; Lothenbach et al. 2011; Lura et al. 2001; Valcuende et al. 2015). Overall, cementitious properties of GGBS depend on its chemical composition, fineness, glass content and alkali concentration of the reacting system (Lothenbach et al. 2011; Siddique 2014). GGBS generally contains less alkali compounds than PC clinker, which leads to lower potassium and sodium concentrations in blended systems over time. Hydroxide concentrations are also lower in the presence of high GGBS contents. In addition to lower alkali content, $\mathrm{pH}$ can be decreased in GGBS pore solution due to formation of reduced sulphur species, such as sulphide (HS$\left.{ }^{-}\right)$, sulphite $\left(\mathrm{SO}_{3}{ }^{2-}\right)$ and thiosulfate $\left(\mathrm{S}_{2} \mathrm{O}_{3}{ }^{2-}\right)$. Calcium, silicon and aluminium concentrations do not change significantly over 
of replacement ( $>75 \mathrm{wt} \%$ of the binder), GGBS can have a strong influence on the alkalinity of cementitious system.

The physical presence of GGBS leads to filler effect, resulting in higher reaction degree of the clinker phase during early ages (dilution effect) (Lothenbach et al. 2011; Scrivener et al. 2015b). Moreover, refinement of pores by GGBS increases tensile stress generated by water menisci in the capillaries (Lura et al. 2001; Tazawa and Miyazawa 1995; Valcuende et al. 2015). Consequently, GGBS may increase autogenous shrinkage and thus may lead to a high cracking susceptibility, trigged by selfdesiccation processes of cementitious materials (Bouasker et al. 2014; Jiang et al. 2014; Lee et al. 2006; Lothenbach et al. 2011; Lura et al. 2001; Scrivener et al. 2015a; Shen et al. 2016; Valcuende et al. 2015). This cracking formation may have a severe impact on concrete durability; it establishes interconnections and increases permeability, facilitating entrance of aggressive agents.

In order to mitigate this negative effect of autogenous shrinkage, superabsorbent polymers (SAP) can be introduced as a novel admixture for internal curing (Hasholt et al. 2012; Jensen and Hansen 2002; Mechtcherine et al. 2013; Mignon et al. 2017; Snoeck et al. 2015; Wehbe and Ghahremaninezhad 2017). SAPs are polyelectrolyte hydrogels with high ability to bind water molecules to their polymer chains due to their hydrophilicity (Jensen and Hansen 2001; Mechtcherine and Reinhardt 2012). This water absorption leads to formation of a swollen product that store and release water over time.

Hydroxides of alkali metals, usually sodium or potassium, can be considered among the primary trunk chains to partially neutralize and prevent these chains from dissolving by forming a three-dimensional network (Mechtcherine et al. 2015; Mechtcherine and Reinhardt 2012). Moreover, SAPs modifications by alkalis as functional filler can reduce costs of their production as well as increase their water absorption capacities ( $\mathrm{Li}$ et al. 2005). For instance, in a non-modified polyacrylamide network, $-\mathrm{CONH}_{2}$ groups (bonded onto the polymer chains) can interact with each other by hydrogen bonding. This causes an increase in crosslinking density and results in a tighter network, leading to a lower polymeric expansion in water. However, when potassium or sodium salts are added into the chains, these ions can weaken the formation of hydrogen bonds between $-\mathrm{CONH}_{2}$ groups. Consequently, it decreases the effective crosslinking density and helps to increase water absorption capacity (Flory and Rehner 1943). However, there is an optimal content of alkalis to acquire the 
maximum SAP water absorption. Values above $6.6 \mathrm{wt} \%$ for potassium (Chu et al. 2008) and $10 \mathrm{wt} \%$ for sodium ( $\mathrm{Li}$ et al. 2005) may lead to a significant reduction of water absorbency due to the increased ionic concentration of external aqueous solution.

Moreover, as polyelectrolytes networks, SAPs can potentially exchange ions with ionic components in solution (Horie et al. 2004; Jensen and Hansen 2001). The absorbable amount of liquid and the storage stability, therefore, depend on SAP grading and molecular composition, as well as ions dissolved in the surrounding solution (Mechtcherine et al. 2015; Siriwatwechakul et al. 2012).

Most of the investigations with SAPs for construction purposes has been based on hardened properties of cementitious matrices, predominantly using ordinary Portland cements (Jensen and Hansen 2001; Mechtcherine and Reinhardt 2012; Schröfl et al. 2017). However, their chemical interactions with blended composites (for example with GGBS) are still unclear and deficient (Beushausen et al. 2014; Klemm and Almeida 2018; Snoeck et al. 2015). Understanding of SAP's performance is essential in decision-making process and selection of suitable type of SAP for different cementitious systems (Sikora and Klemm 2015; Siriwatwechakul et al. 2012). In case of GGBS matrices, polymers with higher water storage capacity and higher retention ability may display better effectiveness in providing additional water for longer reactions (Almeida and Klemm 2018). This is because GGBS has a lower rate of hydration compared to the clinker phases (Lothenbach et al. 2011, 2012; Scrivener et al. 2015b).

This paper, therefore, aims to stress the importance of considering different types of cement in SAP performance by assessing the effect of GGBS on water absorption capacity and stability of SAPs (partially neutralized by sodium and potassium). The analyses were based on experimental data for SAPs swelling capacity and kinetics of the absorption, $\mathrm{pH}$ of binder solutions over time, as well as mechanical properties of PC-GGBS mortars. 
117 Three types of superabsorbent polyelectrolytes (SAP X, Y and Z) of modified polyacrylamide with different water absorption capacities have been studied. They are crosslinked with different concentrations of alkalis salts (sodium and potassium). The polymer behaviour has been evaluated in different systems: deionized water (DI), PC and GGBS filtrates, and PC-GGBS mortars. While Portland cement (PC) systems were prepared with $100 \%$ of CEM I 52.5N (BS EN 197-1 2011), GGBS systems comprised 75\% of ground granulated blastfurnace slag (GGBS) (BS EN 15167-1 2006) and 25\% of CEM I. Low reactivity of GGBS requires an alkaline activator to raise $\mathrm{pH}$ in the vicinity of the slag, This can be provided by $\mathrm{CH}$ and alkali hydroxides from CEM I hydration (Provis 2014; Thomas 2011). Table 1 shows the physical and chemical analysis of PC and GGBS used in the experimental programme.

Table 1. Chemical and physical characterization of $P C$ and $G G B S$

Filtrate solutions have been prepared in the proportion of water/binder $(\mathrm{w} / \mathrm{b})$ ratio $5($ Mechtcherine et al. 2018). Binders (PC and GGBS) have been immersed in deionised water for $24 \mathrm{~h}$ with a mechanical stirrer, followed by filtration to separate binder slurry and the used filtrate solution (Mechtcherine et al. 2018; Mignon et al. 2015; Schroefl et al. 2015; Snoeck et al. 2014b). Although the ionic concentrations of diluted filtrates and pore solutions differ, all relevant ions for SAP sorptivity analysis (i.e., $\mathrm{Na}^{+}, \mathrm{K}^{+}, \mathrm{Ca}^{2+}, \mathrm{OH}^{-}$and $\mathrm{SO}_{4}{ }^{2-}$ ) are well represented in filtrate solutions (Kang et al. 2017; Schroefl et al. 2015; Schröfl et al. 2012, 2017; Zhu et al. 2015).

Mortars have been produced in the proportion of $\mathrm{w} / \mathrm{b}=0.5$, binder : fine sand $=1: 2$, and $\mathrm{SAP}=0.25 \%$ by binder mass. Mixing procedure was the same used in previous studies (Almeida and Klemm 2016a, 2018; Mechtcherine et al. 2013; Schröfl et al. 2012). Dry SAP particles were pre-blended with shows mortars compositions used in the experimental programme. 
144 Particle sizes of SAPs were evaluated by Laser Diffraction (Malvern Mastersizer X).

145 Shape and size were also analysed by the Scanning Electron Microscopy - SEM (Carl Zeiss EVO 50).

146 Samples were not coated and observations were carried out in high vacuum mode, accelerating 147 voltage (EHT) of $15 \mathrm{kV}$ and working distance (WD) of $9 \mathrm{~mm}$.

SAPs chemical characteristics were obtained from X-ray map data by the SEM-linked to the Energy

Disperse X-ray spectrometer - EDX (AZtecEnergy acquisition software with the X-MaxNand X-act Silicon Drift Detector).

pH has been analysed (Fisher Scientific accumet AP110 pH Meter) in SAP solutions with deionised water, PC filtrate and GGBS filtrate for 7 days. $0.3 \mathrm{~g}$ of SAP has been kept in a tea-bag and immersed in 100ml of solution (Schröfl et al. 2017). pH of PC and GGBS filtrates only were also evaluated. For all analysis, SAP samples were tested in triplicate and stored in sealed containers under laboratory conditions $\left(\mathrm{T}=21 \pm 2{ }^{\circ} \mathrm{C}\right.$ and $\left.\mathrm{RH}=40 \pm 5 \%\right)$.

Sorption characteristics were evaluated by the tea-bag method (Mechtcherine et al. 2018; Schroefl et al. 2015; Schröfl et al. 2012, 2017) in deionised water (DI), PC and GGBS filtrates. Masses of SAP gel were recorded at 1, 5, 10,30,60, $180 \mathrm{~min}$, and 1, 2 and 3 days after tea-bag immersion. After that period, carbonation of cement slurry solution can significantly change $\mathrm{pH}$ and hence affect the SAP absorption behaviour, as verified by $\mathrm{pH}$ analysis. Before each mass record, tea-bag containing waterswollen SAP was placed on a dry tissue and gently wiped for a short time (max $30 \mathrm{~s}$ ). This was to remove excess and weakly bound liquid. After weighting, the tea-bag with hydrogel was returned to test solution until the next weighing step.

Water absorption capacities (WAC), were calculated by WAC $=\left(m_{3}-m_{2}-m_{1}\right) / m_{1}$, where $m_{1}$ is the weight of dry SAP, $\mathrm{m}_{2}$ is the mass of tea-bag, and $\mathrm{m}_{3}$ is the weight of water-swollen sample. WAC was expressed in grams of water per gram of dry SAP. The average WAC for three specimens per solution has been used for further analysis (Mechtcherine et al. 2018; Schröfl et al. 2017). A potential drawback of this method is commonly attributed to residual interparticle (capillary) liquid that may remain within the samples during wiping and weighting process (Kang et al. 2017; Schröfl et al. 2012, 2017). Also, the constraint from SAP particles located on the exterior could decrease the 
171 absorption of SAP particles in the interior. However, recent studies showed that no decisive

172 conclusion on these issues can be drawn at this stage (Mechtcherine et al. 2018). Despite these

173 concerns, the tea-bag gravimetric method is one of the most common and widely accepted

174 quantification techniques for SAPs sorptivity assessment, and has been proved to be more practical in

175 terms of time dependent study (Mechtcherine et al. 2018; Schroefl et al. 2015; Schröfl et al. 2012, 176 2017).

177

\section{Properties of GGBS-PC mortars}

Fresh and hardened properties of GGBS-PC mortars modified by SAPs have been evaluated. Flow table method (BS EN 1015-3 2006) was performed in triplicate. Compressive and flexural strengths tests (BS EN 1015-11 2006) were carried out after 7, 14 and 28 days. Specimens were cast into prismatic moulds $\left(160 \times 40 \times 40 \mathrm{~mm}^{3}\right)$ and cured in climate chamber $\left(\mathrm{T}=21 \pm 2{ }^{\circ} \mathrm{C}\right.$ and $\mathrm{RH}=40 \pm$ 5\%) until the date of testing. For flexural strength test, three prims were broken providing six halves which, in turn, were used for compressive strength determination (BS EN 1015-11 2006). SEM micrographs were also obtained in order to evaluate porosity of GGBS mortars at 28 days (this analysis followed the same procedure described in 2.2).

\section{Results and Analysis}

Physical and chemical characteristics of SAP

Fig. 1 shows results of particle size distribution of the studied SAPs.

Fig. 1. Particle size distribution of the studied SAPs

Although slight differences in their distribution have been noticed (mode values for SAP Z $>$ SAP X

$>$ SAP Y), all samples had the same particle size range, predominantly between 20 and $150 \mu \mathrm{m}$. This similar size range and irregular shape can be observed in the SEM micrographs (Fig. 2).

Fig. 2. The SEM micrographs of the studied SAPs

Table 3 show results of SAPs chemical composition (by EDX) obtained from the map sum spectrum of all X-ray data collected. 
Different alkalis content $(\mathrm{Na}+\mathrm{K})$ has been found in the composition of SAPs: $4.0 \%, 8.8 \%$ and $12.3 \%$ for SAP X, SAP Y and SAP Z, respectively. Hydroxides of alkali metals are often used for partial neutralization of polyelectrolytes (SAPs) (Jensen and Hansen 2001; Kang et al. 2017; Krafcik and Erk 2016; Mechtcherine and Reinhardt 2012; Schröfl et al. 2017; Zhu et al. 2015). These polymers dissociate in aqueous solutions and the charged molecular chains play a fundamental role in determining structure, stability and interactions of various molecular assemblies (Visakh et al. 2014). Fig. 3 shows $\mathrm{pH}$ analysis of SAP solutions over period of 7 days. Standard deviations were below 0.1 for all measurements. $\mathrm{pH}$ values for all SAP samples in DI water did not change significantly over time. SAP X presented $\mathrm{pH}$ around 6.8, while SAP Y and Z, about 7.4 and 7.2, respectively. This lower $\mathrm{pH}$ for SAP $\mathrm{X}$ is related to the lower alkali concentration compared to the other polymers. Above the content shown by SAP Y in DI water (8.8\%, Table 3), no significant difference was observed in $\mathrm{pH}$. However, in cementitious solutions, $\mathrm{pH}$ had a considerable drop after the third day due to carbonation effect for all SAPs systems.

Fig. 3. $p H$ analysis of SAP solutions in deionised water (DI), PC and GGBS filtrates

Regarding reference solution (without SAP), lower pH of GGBS filtrate compared to PC solution is related to decreased alkalis and hydroxide concentrations, as well as to formation of reduced sulphur species (Vollpracht et al. 2016). However, when SAPs were added to the solutions, the changes in alkalinity were very dependent on the type of cementitious system. All SAP samples had a stable interaction with PC filtrate; scatter of $\mathrm{pH}$ results was less than 0.1. In contrast, a significant change could be observed when different SAPs were used in GGBS solution, especially when carbonation took place. All SAP solutions showed higher $\mathrm{pH}$ when compared to the pure GGBS filtrate after the second day (see Arrow in Fig. 3). Most likely this was due to potential formation of chemical complexes between alkalis from polymers network and species from GGBS solution (as further discussed in Fig. 6). In particular, SAP $\mathrm{X}$ showed the same behaviour as in PC system after carbonation, indicating that this polymer is the most stable SAP in both cementitious systems. In turn, SAP Y and $\mathrm{Z}$ had the highest $\mathrm{pH}$ values after the second day compared to both PC and GGBS solutions. It suggests their higher $\mathrm{pH}$-sensitivity to the changes in cementitious concentrations (Mignon et al. 2014). 
Therefore, alkalis in concentration up to $4 \mathrm{wt} \%$ (defined by SAP X, Table 3) were able to interact with reduced sulphur species formed in GGBS aqueous solution, keeping the same pH level of a PC system (after carbonation). Above this limit (for SAP Y and Z), increased $\mathrm{pH}$ was recorded due to the excess of alkalis in SAPs composition. There may be a chemical interaction trigged by polymers ions exchange $\left(\mathrm{Na}^{+}\right.$and $\left.\mathrm{K}^{+}\right)$with ionic components of GGBS solution (as further discussed) (Horie et al. 2004; Jensen and Hansen 2001). This interaction was observed until the seventh day, when alkalinity level of all systems seems to converge at a $\mathrm{pH}$ value around 10 .

\section{SAP absorption capacity and kinetics}

Fig. 4 shows sorption behaviour of SAPs in DI water by tea-bag method.

Fig. 4. Sorption behaviour of SAPs in DI water (left: up to 180 min; right: up to 3 days)

Two stages of absorption could be observed in DI water. During the first stage, an initial intensified swelling took place throughout the first $30 \mathrm{~min}$. Absorption capacity values were around 240, 265 and $355 \mathrm{~g} / \mathrm{g}$, respectively for Z, X and Y samples, with standard deviation lower than $10 \mathrm{~g} / \mathrm{g}$. During the second stage, a progressive water absorption up to SAP full capacity could be observed (around the second day). This additional absorption was more pronounced for samples $\mathrm{Y}$ and $\mathrm{Z}$; the increment was in the order of $10 \%, 25 \%$ and $40 \%$ respectively for SAPs X, Y and Z.

Although SAPs $\mathrm{Y}$ and $\mathrm{Z}$ showed similar behaviour, there was a difference in their maximum absorption capacities due to different alkalis contents. In this case, $\mathrm{K}^{+}$concentration seemed to be the main responsible factor for reducing absorbency with values above $6.6 \mathrm{wt} \%$ (Chu et al. 2008). This value is aligned with potassium contents of the studied SAPs and their respective water absorption capacities: SAP Y $\left(3.2 \mathrm{wt} \% \mathrm{~K}^{+}\right.$and $\left.440 \mathrm{~g} / \mathrm{g}\right)$ and SAP Z $\left(12.0 \mathrm{wt} \% \mathrm{~K}^{+}\right.$and $\left.340 \mathrm{~g} / \mathrm{g}\right)$.

Moreover, SAPs sorption behaviour significantly changes when PC-GGBS systems were considered (Fig. 5); not only in a substantial drop of water absorption capacity (around 10x less), but also in storage and release of water.

Fig. 5. Sorption behaviour of SAPs in cementitious solutions (left: up to 180 min; right: up to 3 days). Arrows in the right graph indicate the difference between absorbency in PC and GGBS systems for all SAPS 
Considerable reduction in overall swelling capacity (compared to DI water) was due the presence of dissolved cations in binder filtrates, especially $\mathrm{K}^{+}, \mathrm{Na}^{+}, \mathrm{Mg}^{2+}$ and $\mathrm{Ca}^{2+}$ (Mignon et al. 2015). While SAP Y had the highest capacity (46 g/g), SAP X and Z had similar maximum absorption values: 39 and $38 \mathrm{~g} / \mathrm{g}$, respectively, with standard deviation lower than $1 \mathrm{~g} / \mathrm{g}$. All of them were reached during the first $30 \mathrm{~min}$ in both PC-GGBS systems. After that, a considerable release took place especially for SAP Y and Z; this was even more pronounced in GGBS solution.

In general, particles sizes have a great influence on kinetics of SAPs (Esteves 2010; Mechtcherine et al. 2015), and it could potentially be observed in the test with deionised water. SAP Y, the finest polymer, had the fastest water intake, while SAPs X and Z had similar absorption in the first 10 min. However, considering the small range between the particle sizes (Fig. 1), the effect of SAP diameters was not noted in cementitious solutions (Fig. 5). When both PC and GGBS filtrates are considered, SAP Z (with the largest particles) showed the fastest water absorption, contradicting the concept of the finer particle the faster absorption. Its faster absorptivity may be related to its high alkali content that increases charge concentration of the system. The high amount of $\mathrm{K}^{+}$in SAP Z increases osmotic pressure difference between the polymer and the cementitious aqueous solutions, which results in a faster water absorbency ( $\mathrm{Li}$ et al. 2005). Thus, particularly for this study, it seems that the type of polymer in terms of chemical composition was the main factor influencing sorption characteristics of the studied SAPs in cementitious systems.

In PC solution, after the max WAC is reached, SAPs Y and Z started to release water: up to the first day for SAP Y, and up to the second day for SAP Z. Thereafter, both SAPs had the ability to reabsorb water up to its max WAC (reached during the first $30 \mathrm{~min}$ ).

However, in GGBS system, this initial release of water was higher (for both SAPs) and no further absorption was noted. This may indicate degradation of SAP Y and Z, due to the loss of their stability of water retention.

In turn, SAP X, although had a slight increment of absorbency in PC solution, it kept nearly unaltered over time in GGBS system. It indicates higher stability of this polymer in both cementitious solutions. Thus, its alkali content of $4 \mathrm{wt} \%$ may rule the stability of the polymer in GGBS systems, which seems 
enough to bind with reduced sulphur species. Above this concentration, exchange of ions between polymers and aqueous solutions may lead to low ability to store water.

This effect of SAP instability was described as polymer degradation (Mignon et al. 2014, 2015; Tachibana et al. 2017). It means a decrease of network integrity; chain junction knots can hydrolyse resulting in a drastic swelling reduction. It has been reported that solutions with higher cation concentrations (especially divalent cations) are concomitant with reduced hydrolysis (Dho and Choi 1995; Mignon et al. 2015). Indeed, desorption capacity was even higher in GGBS system (with reduced $\mathrm{Ca}^{2+}$ content, see Table 1), indicating greater sensitivity of SAPs $\mathrm{Y}$ and Z. The difference between absorption/storage capacities in PC and GGBS systems was clearly higher for these SAPs (when compared to SAP X) during the first three days (see arrows in Fig. 5); almost no difference was noted for SAP X during the first 180 min of test.

These results are aligned with $\mathrm{pH}$ analysis (Fig. 3) where SAP Y and $\mathrm{Z}$ have also showed instability in GGBS system, most likely due to their high alkalinity (Table 3). Addition of $\mathrm{K}^{+}$and $\mathrm{Na}^{+}$in SAPs chains have the ability to weaken hydrogen bonds formation and, in consequence, facilitate (or induce) complex bonds between the polymeric network and metal ions from cementitious solutions. Moreover, the presence of $\mathrm{S}^{2-}$ in SAP X could indicate that this ion contributes to greater polymer stabilization by forming disulphide bonds. These are very strong bonds able to hold polymers in their respective conformations, and therefore, play an important role in their folding and stability (Brandt et al. 2017). Disulphide bonds can only be cleaved by external stimulus, such as oxidation-reduction potential (Tachibana et al. 2017). However, as SAP Y also contains sulphide, it is suggested that high alkali content seems to be the main responsible factor for SAP Y and Z degradations in GGBS systems.

Surrounding cementitious solutions with univalent cations (e.g. $\mathrm{K}^{+}$and $\mathrm{Na}^{+}$) have the easiest interaction with a crosslinked potassium/sodium hydrophilic network, followed by mediums with divalent $\left(\mathrm{Mg}^{2+}\right.$ and $\left.\mathrm{Ca}^{2+}\right)$ and then trivalent $\left(\mathrm{Al}^{3+}\right.$ and $\left.\mathrm{Fe}^{3+}\right)$ cations. Thus, water absorption capacity of SAP and its storage stability decrease with the increase of ionic strength of external saline solution; the stronger salt ions bonds (from solution), the lower is the effect on the charge of SAP chain. Thus, 
the ease of interaction is in the following order: $\mathrm{K}^{+}=\mathrm{Na}^{+}>\mathrm{Mg}^{2+}>\mathrm{Ca}^{2+}>\mathrm{Al}^{3+}>\mathrm{Fe}^{3+}$ (Chu et al. 2008).

It is worth noting that potassium/sodium modified SAPs are more likely to interact with $\mathrm{Mg}^{2+}$ than with $\mathrm{Ca}^{2+}$ from cementitious solutions. This ionic preference can explain how SAPs $\mathrm{Y}$ and $\mathrm{Z}$ had more unstable performances in GGBS systems compared to PC solutions; $\mathrm{MgO}$ content is 4.4 times higher in GGBS than PC (Table 1). The presence of divalent cations form strong complexes with the polymer chain and act as additional cross-linker, resulting in low swelling degree (Mignon et al. 2015). $\mathrm{Al}_{2} \mathrm{O}_{3}$ can also contribute to form complex bonds with those SAPs in GGBS environments, since $\mathrm{Ca}^{+2}$ concentration is lower than PC and this ion is also "disputed" with carbonation reactions (observed in both PC-GGBS filtrates). Univalent cations content seems to be very low compared to other elements, especially in GGBS systems (lower than PC's), resulting in negligible interactions with SAPs. Such interaction is schematically represented in Fig. 6, particularly with $\mathrm{Mg}^{2+}$ and $\mathrm{Al}^{3+}$ ions.

Fig. 6. Polyacrylamide structures and their modifications (adapted from Chu et al. 2008)

Therefore, SAP X is more stable and less sensitive to the type of cement, in particular in PC-GGBS matrices. It seems that there is a certain limit of alkali content in SAPs of around $4 \mathrm{wt} \%$ that can retain stability of GGBS system similar to PC solution. These alkalis can interact with reduced sulphur species ( $\mathrm{HS}^{-}, \mathrm{SO}_{3}{ }^{2-}$ and $\mathrm{S}_{2} \mathrm{O}_{3}{ }^{2-}$ ) formed in GGBS aqueous solution that generally are not found in PC systems (due to its higher alkali concentration compared to GGBS). Consequently, SAP's alkalis (up to $4 \mathrm{wt} \%$ ) combined with GGBS reduced sulphur ions keep SAP-GGBS system stable similarly to the SAP-PC system.

Above this limit, additionally to this chemical interaction, ion-exchange can take place between "extra" SAP alkalis $\left(\mathrm{Na}^{+}\right.$and $\left.\mathrm{K}^{+}\right)$and additional ions of $\mathrm{Mg}^{2+}$ and $\mathrm{Al}^{3+}$ from aqueous solution (compared to the amount of these ions in PC system). This ion-exchange can lead, however, to SAPs degradation and hence, reducing their stability in water retention. 
337 Fig. 7 compares results of consistency of fresh mortars modified by SAPs with their respective reference samples. Overall, all SAPs decreased flowability for both PC-GGBS systems (Filho et al. 2012).

Fig. 7. Flow-table results of PC-GGBS mortars modified by SAPs

Duration of flow-table test had a significant impact on the results. SAP X had a slightly lower absorption rate compared to SAP Y and $\mathrm{Z}$ in the first $30 \mathrm{~min}$ (Fig. 5). In consequence, this polymer $\mathrm{X}$ resulted in the highest flow values among SAP mortars, even though its final WAC was between Y and $\mathrm{Z}$ samples in cementitious filtrate solutions. Moreover, addition of sand can imply a "dilution effect" of PC-GGBS ions. Sorption behaviour of SAPs obtained in mortars (by flow-table test) was similar to that in DI water (by tea-bag method after the first day). The use of mechanical mixer for mortars preparation could have stimulated SAPs to reach their maximum WAC during mixing/casting procedures. Thus, SAP X had the lowest absorption capacity in mortars, as in DI water.

Results of mortars compressive strength over the first month are shown in Fig. 8. Overall, GGBS has reduced compressive strength for all samples due to its slower hydration rate. As reported by Lothenbach et al. (2012) about 90\% of GGBS hydrated during 3.5 years. Moreover, overall porosity of PC-GGBS matrices is higher due to the lower total volume of C-S-H formed by GGBS when compared to pure PC systems (Lothenbach et al. 2011).

Fig. 8. Compressive strength results of PC-GGBS mortars modified by SAPS

The type of SAP had a greater impact than the type of binder. In PC mortars, all compressive strength values were comparable. In contrast, when GGBS was considered, a clear pattern was observed for all ages: while SAP X was very similar to the reference sample, SAP Y and Z had the lowest strength values during the first 28 days. In particular for SAP Y, whose higher WAC could have aggravated mechanical properties of mortars. This is because greater swelling rate may lead to macro-pore formation in the hardened state (Almeida and Klemm 2018; Farzanian et al. 2016; Farzanian and Ghahremaninezhad 2017; Pourjavadi et al. 2013; Schröfl et al. 2012; Snoeck et al. 2014a).

Their lower compressive strength results (for SAP Y and Z) may be also related to the instability in GGBS systems. Both SAPs have not showed a reliable capacity to store water for longer periods (Fig. 
5). Thus, after polymer collapses, SAPs left behind larger pores, which could not be refilled with hydration products due to the lack of water. It is very likely that this collapse of SAP took place in the first week of hydration, since the pattern was the same for all studied ages. In summary, reduction in compressive strength for SAP Y and Z mortars (during the first month) can be related to two main concomitant factors: larger pores formation and low ability to water retention. Their macropores are even larger than those formed by SAP X, due to their higher WAC (collapsed SAPs). Once these larger pores are formed, there is not enough water to induce longer GGBS reactions, and hence, to refill those macropores with later hydration products. This outcome is aligned with previous detailed studies on microstructure alteration of SAP-PC-GGBS mortars (Almeida and Klemm 2016b, 2017, 2018). Fig. 9 illustrates these larger macropores formation at 28 days, especially for SAPs Y and Z mortars.

Fig. 9. SEM micrographs of GGBS mortars at 28 days (indication of larger pores in samples modified by SAP Y and $S A P Z)$

Therefore, SAPs chemical composition, in particular its potassium/sodium salt modifications, has a significant influence on compressive strength. This is even more evident in GGBS matrices. Regarding flexural strength, no significant difference in the overall pattern could be identified between specimens modified by SAPs (Fig. 10).

However, at 28 days, SAP-GGBS mortars showed less variation in results than SAP-PC mortars when compared to their respective reference samples. This could be explained by the sensitiveness of the test to smaller pores. GGBS refines capillaries and leads to a denser structure of micropores (below 50 nm for high GGBS content) (Almeida and Klemm 2017, 2018; Li et al. 2010). Thus, results of flexural strength for GGBS mortars are more similar to each other, regardless the addition of SAP. In contrast, a slight reduction in strength can be observed in some PC mortars modified by SAP. Thus, the type of SAP had a considerable effect on compressive strength of GGBS mortars up to 28 days. However, no significant impact was observed on flexural strength, especially for high GGBS contents. 


\section{Conclusions}

393 Based on the experimental data, the following can be concluded:

- Behaviour of SAPs with alkali content around $4 \mathrm{wt} \%$ in GGBS systems is similar to a stable PC system. Up to this concentration, sodium/potassium ions may bind with reduced sulphur

Therefore, although the studied SAPs have been designed for a stable performance in Portland cement systems, the excess of alkalis in SAPs compositions leads to chemical interactions with GGBS aqueous solution (with reduced $\mathrm{pH}$ ) and hence, to instability of the polymeric network. 
420 The authors acknowledge CNPq (National Council for Scientific and Technological Development -

421 Brazil) for the financial support (Grant Number: 204097/2014-2), and BASF for SAPs supply.

422

\section{References}

424

Almeida, F. C. R., and Klemm, A. J. (2016a). "Effect of Superabsorbent Polymers (SAP) on Fresh State Mortars with Ground Granulated Blast-Furnace Slag (GGBS)." 5th International Conference on the Durability of Concrete Structures, Shenzhen.

Almeida, F. C. R., and Klemm, A. J. (2016b). "Evaluation of hardened state properties of GGBS-PC mortars modified by superabsorbent polymers (SAP).” International RILEM Conference on Materials, Systems and Structures in Civil Engineering, Lyngby, 11-20.

Almeida, F. C. R., and Klemm, A. J. (2017). "Microstructure alteration of PC-GGBS mortars by superabsorbent polymers ( SAP ).” 14th International Conference on Durability of Building Materials and Components, PRO 113, Ghent, 205-216.

Almeida, F. C. R., and Klemm, A. J. (2018). "Efficiency of internal curing by superabsorbent polymers (SAP) in PC-GGBS mortars." Cement and Concrete Composites, 88, 41-51.

Almeida, F. C. R., Sales, A., Moretti, J. P., and Mendes, P. C. D. (2015). "Sugarcane bagasse ash sand (SBAS): Brazilian agroindustrial by-product for use in mortar." Construction and Building Materials, Elsevier Ltd, 82, 31-38.

Beushausen, H., Gillmer, M., and Alexander, M. (2014). “The influence of superabsorbent polymers on strength and durability properties of blended cement mortars." Cement and Concrete Composites, Elsevier Ltd, 52, 73-80.

Bouasker, M., Khalifa, N. E. H., Mounanga, P., and Ben Kahla, N. (2014). "Early-age deformation and autogenous cracking risk of slag-limestone filler-cement blended binders." Construction and Building Materials, 55, 158-167.

Brandt, N. N., Chikishev, A. Y., and Kruzhilin, V. N. (2017). "Raman study of the cleavage of 

B.V., $89,75-80$.

BS EN 1015-11. (2006). "Methods of Test for Mortar for Masonry - Part 11: Determination of Flexural and Compressive Strength of Hardened Mortar.” British Standard.

BS EN 1015-3. (2006). "Methods of Test for Mortar for Masonry - Part 3: Determination of consistence of fresh mortar (by flow table)." British Standard.

BS EN 15167-1. (2006). "Ground granulated blast furnace slag for use in concrete, mortar and grout Part 1: Definitions, specifications and conformity criteria." British Standard.

BS EN 197-1. (2011). “Cement Part 1: Composition, Specifications and Conformity Criteria for Common Cements." British Standard, 50.

Chu, M., Zhu, S.-Q., Huang, Z.-B., and Li, H.-M. (2008). "Influence of Potassium Humate on the Swelling Properties of a Poly(acrylic acid-co-acrylamide)/ Potassium Humate Superabsorbent

Damineli, B. L., Kemeid, F. M., Aguiar, P. S., and John, V. M. (2010). "Measuring the eco-efficiency of cement use." Cement and Concrete Composites, Elsevier Ltd, 32(8), 555-562.

Dho, S. K., and Choi, C. H. (1995). "Effects of divalent cations on alkaline hydrolysis of

Divsholi, B. S., Lim, T. Y. D., and Teng, S. (2014). “Durability Properties and Microstructure of

Esteves, L. P. (2010). “On the absorption kinetics of superabsorbent polymers.” International RILEM Conference on Use of Superabsorbent Polymers and Other New Additives in Concrete, RILEM, Lyngby, 77-84.

Fairbairn, E. M. R., Americano, B. B., Cordeiro, G. C., Paula, T. P., Toledo Filho, R. D., and Silvoso, 
M. M. (2010). "Cement replacement by sugar cane bagasse ash: CO2 emissions reduction and potential for carbon credits." Journal of Environmental Management, 91(9), 1864-1871.

Farzanian, K., and Ghahremaninezhad, A. (2017). "The effect of the capillary forces on the desorption of hydrogels in contact with a porous cementitious material." Materials and Structures/Materiaux et Constructions, Springer Netherlands, 50(5), 1-15.

Farzanian, K., Pimenta Teixeira, K., Perdigão Rocha, I., De Sa Carneiro, L., and Ghahremaninezhad, A. (2016). "The mechanical strength, degree of hydration, and electrical resistivity of cement pastes modified with superabsorbent polymers." Construction and Building Materials, Elsevier

Filho, R. D. T., Silva, E. F., Lopes, A. N. M., Mechtcherine, V., and Dudziak, L. (2012). “Effect of 
Horie, K., Báron, M., Fox, R. B., He, J., Hess, M., Kahovec, J., Kitayama, T., Kubisa, P., Maréchal, E., Mormann, W., Stepto, R. F. T., Tabak, D., Vohlídal, J., Wilks, E. S., and Work, W. J. (2004). "Definitions of terms relating to reactions of polymers and to functional polymeric materials (IUPAC Recommendations 2003)." Pure and Applied Chemistry, 76(4), 889-906.

Huang, L., Krigsvoll, G., Johansen, F., Liu, Y., and Zhang, X. (2018). "Carbon emission of global construction sector." Renewable and Sustainable Energy Reviews, Elsevier Ltd, 81(June 2017), $1906-1916$.

Jensen, O. M., and Hansen, P. F. (2001). "Water-entrained cement-based materials: I. Principles and theoretical background." Cement and Concrete Research, 31(4), 647-654.

Jensen, O. M., and Hansen, P. F. (2002). "Water-entrained cement-based materials: II. Experimental observations." Cement and Concrete Research, 32, 973-978.

Jiang, C., Yang, Y., Wang, Y., Zhou, Y., and Ma, C. (2014). “Autogenous shrinkage of high performance concrete containing mineral admixtures under different curing temperatures." Construction and Building Materials, 61, 260-269.

John, V. M., and Zordan, S. E. (2001). "Research and development methodology for recycling residues as building materials - A proposal.” Waste Management, 21(3), 213-219.

Kang, S. H., Hong, S. G., and Moon, J. (2017). “Absorption kinetics of superabsorbent polymers (SAP) in various cement-based solutions." Cement and Concrete Research, Elsevier Ltd, 97, $73-83$.

Klemczak, B., and Batog, M. (2016). "Heat of hydration of low-clinker cements: Part I. Semiadiabatic and isothermal tests at different temperature." Journal of Thermal Analysis and Calorimetry, Springer Netherlands, 123(2), 1351-1360.

Klemm, A. J., and Almeida, F. C. R. (2018). “Towards more sustainable construction-application of superabsorbent polymers in cementitious matrices with reduced carbon footprint." MATEC Web of Conferences. 
521 Krafcik, M. J., and Erk, K. A. (2016). "Characterization of superabsorbent poly ( sodium-acrylate acrylamide ) hydrogels and influence of chemical structure on internally cured mortar."

Krivenko, P., Drochytka, R., Gelevera, A., and Kavalerova, E. (2014). "Mechanism of preventing the alkali-aggregate reaction in alkali activated cement concretes." Cement and Concrete

Lee, K. M., Lee, H. K., Lee, S. H., and Kim, G. Y. (2006). “Autogenous shrinkage of concrete Composites, 45, 157-165.

Li, A., Zhang, J., and Wang, A. (2005). "Synthesis, characterization and water absorbency properties of poly(acrylic acid)/sodium humate superabsorbent composite." Polymers for Advanced Technologies, 16(9), 675-680.

Li, S. (2016). "Microstructure and composition characterisation of three 20-year-old GGBS-OPC blended pastes." Construction and Building Materials, Elsevier Ltd, 123, 226-234.

Li, Y., Bao, J., and Guo, Y. (2010). “The relationship between autogenous shrinkage and pore structure of cement paste with mineral admixtures." Construction and Building Materials, Elsevier Ltd, 24(10), 1855-1860.

Loser, R., Lothenbach, B., Leemann, A., and Tuchschmid, M. (2010). "Chloride resistance of concrete and its binding capacity - Comparison between experimental results and thermodynamic modeling." Cement and Concrete Composites, Elsevier Ltd, 32(1), 34-42.

Lothenbach, B., Le Saout, G., Ben Haha, M., Figi, R., and Wieland, E. (2012). "Hydration of a lowalkali CEM III/B-SiO2 cement (LAC).” Cement and Concrete Research, 42(2), 410-423.

Lothenbach, B., Scrivener, K., and Hooton, R. D. (2011). "Supplementary cementitious materials." Cement and Concrete Research, 41(12), 1244-1256.

Lura, P., van Breugel, K., and Maruyama, I. (2001). "Effect of curing temperature and type of cement 
Mechtcherine, V., Gorges, M., Schroefl, C., Assmann, A., Brameshuber, W., Ribeiro, A. B., Cusson, D., Custódio, J., Silva, E. F., Ichimiya, K., Igarashi, S., Klemm, A., Kovler, K., Mendonça Lopes, A. N., Lura, P., Nguyen, V. T., Reinhardt, H.-W., Filho, R. D. T., Weiss, J., Wyrzykowski, M., Ye, G., and Zhutovsky, S. (2013). "Effect of internal curing by using superabsorbent polymers (SAP) on autogenous shrinkage and other properties of a highperformance fine-grained concrete: results of a RILEM round-robin test." Materials and Structures, 47(3), 541-562.

Mechtcherine, V., and Reinhardt, H.-W. (Eds.). (2012). Application of Superabsorbent Polymers ( SAP) in Concrete Construction: State-of-the-Art Report Prepared by Technical Committee 225SAP. Springer, RILEM.

Mechtcherine, V., Secrieru, E., and Schröfl, C. (2015). "Effect of superabsorbent polymers (SAPs) on rheological properties of fresh cement-based mortars - Development of yield stress and plastic viscosity over time." Cement and Concrete Research, 67, 52-65.

Mechtcherine, V., Snoeck, D., Schröfl, C., De Belie, N., Klemm, A. J., Ichimiya, K., Moon, J., Wyrzykowski, M., Lura, P., Toropovs, N., Assmann, A., Igarashi, S., De La Varga, I., Almeida, F. C. R., Erk, K., Ribeiro, A. B., Custódio, J., Reinhardt, H. W., and Falikman, V. (2018). “Testing superabsorbent polymer (SAP) sorption properties prior to implementation in concrete: results of a RILEM Round-Robin Test.” Materials and Structures, 51(1), 28.

Mignon, A., Graulus, G. J., Snoeck, D., Martins, J., De Belie, N., Dubruel, P., and Van Vlierberghe, S. (2014). "pH-sensitive superabsorbent polymers: a potential candidate material for self-healing concrete." Journal of Materials Science, 50(2), 970-979.

Mignon, A., Snoeck, D., Dubruel, P., Vlierberghe, S. Van, and De Belie, N. (2017). "Crack mitigation in concrete: Superabsorbent polymers as key to success?" Materials, 10(3).

Mignon, A., Snoeck, D., Schaubroeck, D., Luickx, N., Dubruel, P., Van Vlierberghe, S., and De Belie, N. (2015). "pH-responsive superabsorbent polymers: A pathway to self-healing of 
Moretti, J. P., Sales, A., Quarcioni, V. A., Silva, D. C. B., Oliveira, M. C. B., Pinto, N. S., and Ramos, L. W. S. L. (2018). "Pore size distribution of mortars produced with agroindustrial waste." Journal of Cleaner Production, Elsevier Ltd.

576

577

Pacheco-Torgal, F., Jalali, S., Labrincha, J., and John, V. M. (Eds.). (2013). Eco-Efficient Concrete. Woodhead Publishing Ltd.

Pourjavadi, A., Fakoorpoor, S. M., Hosseini, P., and Khaloo, A. (2013). "Interactions between superabsorbent polymers and cement-based composites incorporating colloidal silica nanoparticles." Cement and Concrete Composites, 37, 196-204.

Provis, J. L. (2014). "Geopolymers and other alkali activated materials: why, how, and what?" Materials and Structures, 47, 11-25.

Rodrigues, F. A., and Joekes, I. (2011). “Cement industry: Sustainability, challenges and perspectives." Environmental Chemistry Letters, 9(2), 151-166.

Sales, A., and Lima, S. A. (2010). "Use of Brazilian sugarcane bagasse ash in concrete as sand replacement." Waste Management, 30(6), 1114-1122.

Schroefl, C., Mechtcherine, V., Vontobel, P., Hovind, J., and Lehmann, E. (2015). "Sorption kinetics of superabsorbent polymers (SAPs) in fresh Portland cement-based pastes visualized and quantified by neutron radiography and correlated to the progress of cement hydration." Cement and Concrete Research, 75, 1-13.

Schröfl, C., Mechtcherine, V., and Gorges, M. (2012). "Relation between the molecular structure and the efficiency of superabsorbent polymers (SAP) as concrete admixture to mitigate autogenous shrinkage." Cement and Concrete Research, 42(6), 865-873.

Schröfl, C., Snoeck, D., and Mechtcherine, V. (2017). "A review of characterisation methods for superabsorbent polymer (SAP) samples to be used in cement-based construction materials: report of the RILEM TC 260-RSC.” Materials and Structures, 50(4), 197. 
Scrivener, K. L., John, V. M., and Gartner, E. M. (2016). Eco-efficient cements: Potential economically viable solutions for a low-CO2 cement- based materials industry. United Nations Environment Program, Paris.

Scrivener, K. L., Juilland, P., and Monteiro, P. J. M. (2015a). “Advances in understanding hydration of Portland cement." Cement and Concrete Research, 78, 38-56.

Scrivener, K. L., Lothenbach, B., De Belie, N., Gruyaert, E., Skibsted, J., Snellings, R., and Vollpracht, A. (2015b). “TC 238-SCM: hydration and microstructure of concrete with SCMs.” Materials and Structures, 48(4), 835-862.

Shen, D., Wang, X., Cheng, D., Zhang, J., and Jiang, G. (2016). "Effect of internal curing with super absorbent polymers on autogenous shrinkage of concrete at early age." Construction and Building Materials, 106, 512-522.

Siddique, R. (2014). "Utilization (recycling) of iron and steel industry by-product (GGBS) in concrete: Strength and durability properties." Journal of Material Cycles and Waste Management, 16(3), 460-467.

Siddique, R., and Bennacer, R. (2012). "Use of iron and steel industry by-product (GGBS) in cement paste and mortar." Resources, Conservation and Recycling, 69, 29-34.

Sikora, K. S., and Klemm, A. J. (2015). "Effect of Superabsorbent Polymers on Workability and Hydration Process in Fly Ash Cementitious Composites.” Journal of Materials in Civil Engineering, American Society of Civil Engineers, 27(5), 4014170.

Siriwatwechakul, W., Siramanont, J., and Vichit-Vadakan, W. (2012). "Behavior of Superabsorbent Polymers in Calcium- and Sodium-Rich Solutions." Journal of Materials in Civil Engineering, 24(8), 976-980.

Snoeck, D., Jensen, O. M., and De Belie, N. (2015). “The influence of superabsorbent polymers on the autogenous shrinkage properties of cement pastes with supplementary cementitious materials." Cement and Concrete Research, 74, 59-67. 
Snoeck, D., Schaubroeck, D., Dubruel, P., and De Belie, N. (2014a). "Effect of high amounts of superabsorbent polymers and additional water on the workability, microstructure and strength of mortars with a water-to-cement ratio of 0.50." Construction and Building Materials, 72, 148157.

Snoeck, D., Tittelboom, K. V., Steuperaert, S., Dubruel, P., and Belie, N. D. (2014b). "Self-healing cementitious materials by the combination of microfibres and superabsorbent polymers." Journal of Intelligent Material Systems and Structures, 25(1), 13-24.

Tachibana, Y., Baba, T., and Kasuya, K. (2017). "Environmental biodegradation control of polymers by cleavage of disulfide bonds." Polymer Degradation and Stability, Elsevier Ltd, 137, 67-74.

Tazawa, E., and Miyazawa, S. (1995). "Influence of cement and admixture on autogenous shrinkage of cement paste." Cement and Concrete Research, 25(2), 281-287.

Thomas, M. (2011). "The effect of supplementary cementing materials on alkali-silica reaction: A review." Cement and Concrete Research, 41(12), 1224-1231.

Valcuende, M., Benito, F., Parra, C., and Miñano, I. (2015). "Shrinkage of self-compacting concrete made with blast furnace slag as fine aggregate." Construction and Building Materials, 76, 1-9.

Visakh, P. M., Bayraktar, O., and Pico, G. A. (Eds.). (2014). Polyelectrolytes: Thermodynamics and Rheology. Polyelectrolytes: Thermodynamics and Rheology, Springer.

Vollpracht, A., Lothenbach, B., Snellings, R., and Haufe, J. (2016). “The pore solution of blended cements: a review." Materials and Structures, 49(8), 3341-3367.

Wehbe, Y., and Ghahremaninezhad, A. (2017). “Combined effect of shrinkage reducing admixtures (SRA) and superabsorbent polymers (SAP) on the autogenous shrinkage, hydration and properties of cementitious materials." Construction and Building Materials, 138, 151-162.

Zhu, Q., Barney, C. W., and Erk, K. A. (2015). "Effect of ionic crosslinking on the swelling and mechanical response of model superabsorbent polymer hydrogels for internally cured concrete." Materials and Structures, Springer Netherlands, 48(7), 2261-2276. 
Table 1. Chemical and physical characterization of PC and GGBS

\begin{tabular}{|c|c|c|c|}
\hline Parameter & Unit & $\mathrm{PC}$ & GGBS \\
\hline $\mathrm{CaO}$ & $\mathrm{wt} \%$ & 62.44 & 38.53 \\
\hline $\mathrm{SiO}_{2}$ & $w t \%$ & 20.07 & 34.53 \\
\hline $\mathrm{Al}_{2} \mathrm{O}_{3}$ & $\mathrm{wt} \%$ & 4.85 & 13.4 \\
\hline $\mathrm{MgO}$ & $w t \%$ & 2.20 & 9.74 \\
\hline $\mathrm{TiO}_{2}$ & wt $\%$ & - & 0.82 \\
\hline $\mathrm{Fe}_{2} \mathrm{O}_{3}$ & $w t \%$ & 2.72 & 0.21 \\
\hline $\mathrm{SO}_{3}$ & $\mathrm{wt} \%$ & 3.15 & 0.35 \\
\hline $\mathrm{Na}_{2} \mathrm{O}$ & $w t \%$ & 0.31 & 0.17 \\
\hline $\mathrm{K}_{2} \mathrm{O}$ & wt $\%$ & 0.62 & 0.59 \\
\hline $\mathrm{MnO}$ & wt $\%$ & - & 0.22 \\
\hline $\mathrm{Cl}^{-}$ & $w t \%$ & 0.06 & 0.02 \\
\hline LOI & wt $\%$ & 2.77 & 0.64 \\
\hline Bulk density & $\mathrm{kg} / \mathrm{L}$ & 1.28 & 1.11 \\
\hline Specific surface & $\mathrm{m}^{2} / \mathrm{kg}$ & 410 & 390 \\
\hline
\end{tabular}


Table 2. Mix compositions of mortars

\begin{tabular}{|c|c|c|c|c|c|c|c|c|}
\hline \multirow{2}{*}{$\begin{array}{l}\text { Sample } \\
\text { name }\end{array}$} & \multirow{2}{*}{$\begin{array}{c}\text { Type of } \\
\text { SAP }\end{array}$} & \multirow{2}{*}{$\begin{array}{c}\text { PC content } \\
(\%)\end{array}$} & \multirow{2}{*}{$\begin{array}{c}\text { GGBS content } \\
(\%)\end{array}$} & \multicolumn{5}{|c|}{ Mass of materials (g) } \\
\hline & & & & $\mathrm{PC}$ & GGBS & SAP & Sand & Water \\
\hline R0 & - & $100 \%$ & $0 \%$ & 587.0 & - & - & 1174.0 & 293.5 \\
\hline $\mathrm{X} 0$ & SAP X & $100 \%$ & $0 \%$ & 587.0 & - & 1.5 & 1174.0 & 293.5 \\
\hline Y0 & SAP Y & $100 \%$ & $0 \%$ & 587.0 & - & 1.5 & 1174.0 & 293.5 \\
\hline $\mathrm{Z} 0$ & SAP Z & $100 \%$ & $0 \%$ & 587.0 & - & 1.5 & 1174.0 & 293.5 \\
\hline $\mathrm{R} 75$ & - & $25 \%$ & $75 \%$ & 146.8 & 440.3 & - & 1174.0 & 293.5 \\
\hline$X 75$ & SAP X & $25 \%$ & $75 \%$ & 146.8 & 440.3 & 1.5 & 1174.0 & 293.5 \\
\hline Y75 & SAP Y & $25 \%$ & $75 \%$ & 146.8 & 440.3 & 1.5 & 1174.0 & 293.5 \\
\hline $\mathrm{Z75}$ & SAP Z & $25 \%$ & $75 \%$ & 146.8 & 440.3 & 1.5 & 1174.0 & 293.5 \\
\hline
\end{tabular}


Table 3. Chemical composition of the studied SAPs by EDX analysis (by wt\%)

\begin{tabular}{ccccccc}
\hline & \multicolumn{2}{c}{ SAP X } & \multicolumn{2}{c}{ SAP Y } & \multicolumn{2}{c}{ SAP Z } \\
\cline { 2 - 7 } Elements & Average & SD & Average & SD & Average & SD \\
\cline { 2 - 7 } $\mathrm{C}$ & 49.8 & 1.8 & 47.3 & 1.6 & 46.9 & 0.8 \\
\hline $\mathrm{O}$ & 28.2 & 1.0 & 30.8 & 0.5 & 29.3 & 0.5 \\
\hline $\mathrm{N}$ & 12.7 & 0.4 & 11.0 & 0.7 & 11.2 & 0.8 \\
\hline $\mathrm{K}$ & 0.0 & 0.0 & 3.2 & 0.3 & 12.0 & 1.3 \\
\hline $\mathrm{Na}$ & 4.0 & 0.3 & 5.7 & 0.5 & 0.2 & 0.1 \\
\hline $\mathrm{S}$ & 5.3 & 0.5 & 2.1 & 0.2 & 0.3 & 0.1
\end{tabular}

Note: $\mathrm{SD}=$ standard deviation 


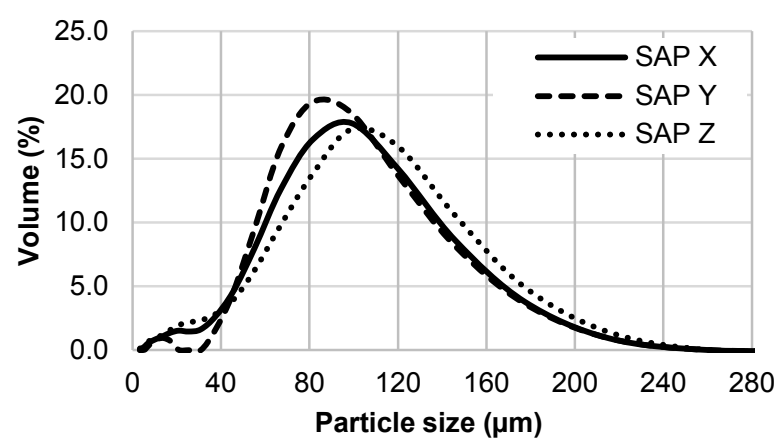

\begin{tabular}{ccccc}
\hline & & SAP X & SAP Y & SAP Z \\
\hline $\mathrm{d}(\mathrm{v}, 0.5)$ & $\mu \mathrm{m}$ & 84.88 & 85.13 & 89.55 \\
$\mathrm{~d}(\mathrm{v}, 0.1)$ & $\mu \mathrm{m}$ & 32.96 & 49.72 & 26.01 \\
mode & $\mu \mathrm{m}$ & 95.19 & 85.74 & 102.51 \\
$\mathrm{~d}(\mathrm{v}, 0.9)$ & $\mu \mathrm{m}$ & 140.00 & 139.64 & 147.24 \\
\hline
\end{tabular}

Fig. 1. Particle size distribution of the studied SAPs 

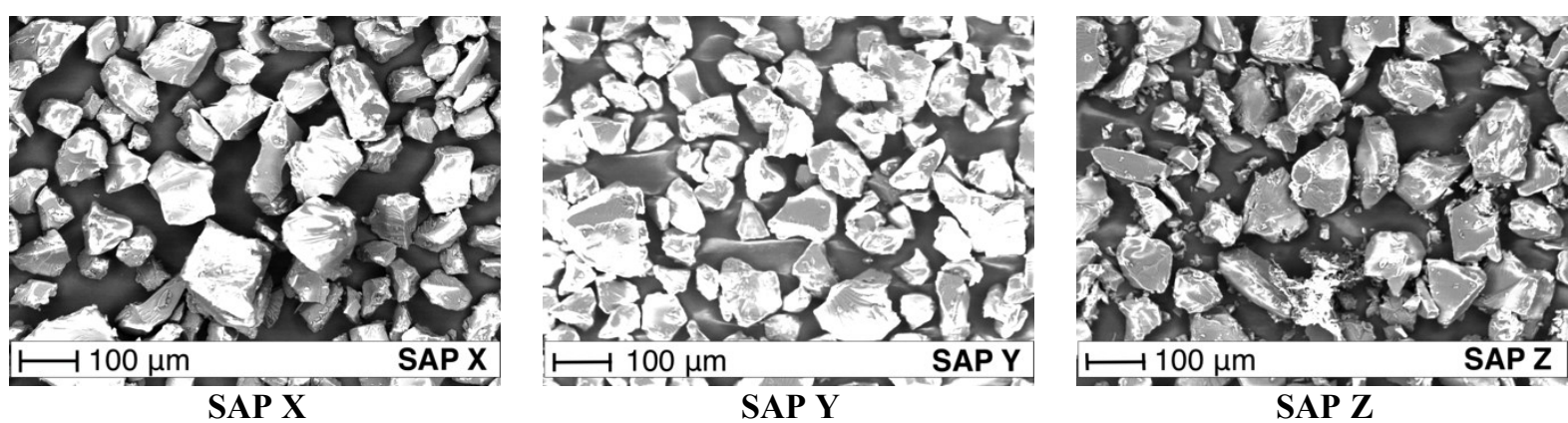

Fig. 2. The SEM micrographs of the studied SAPs 

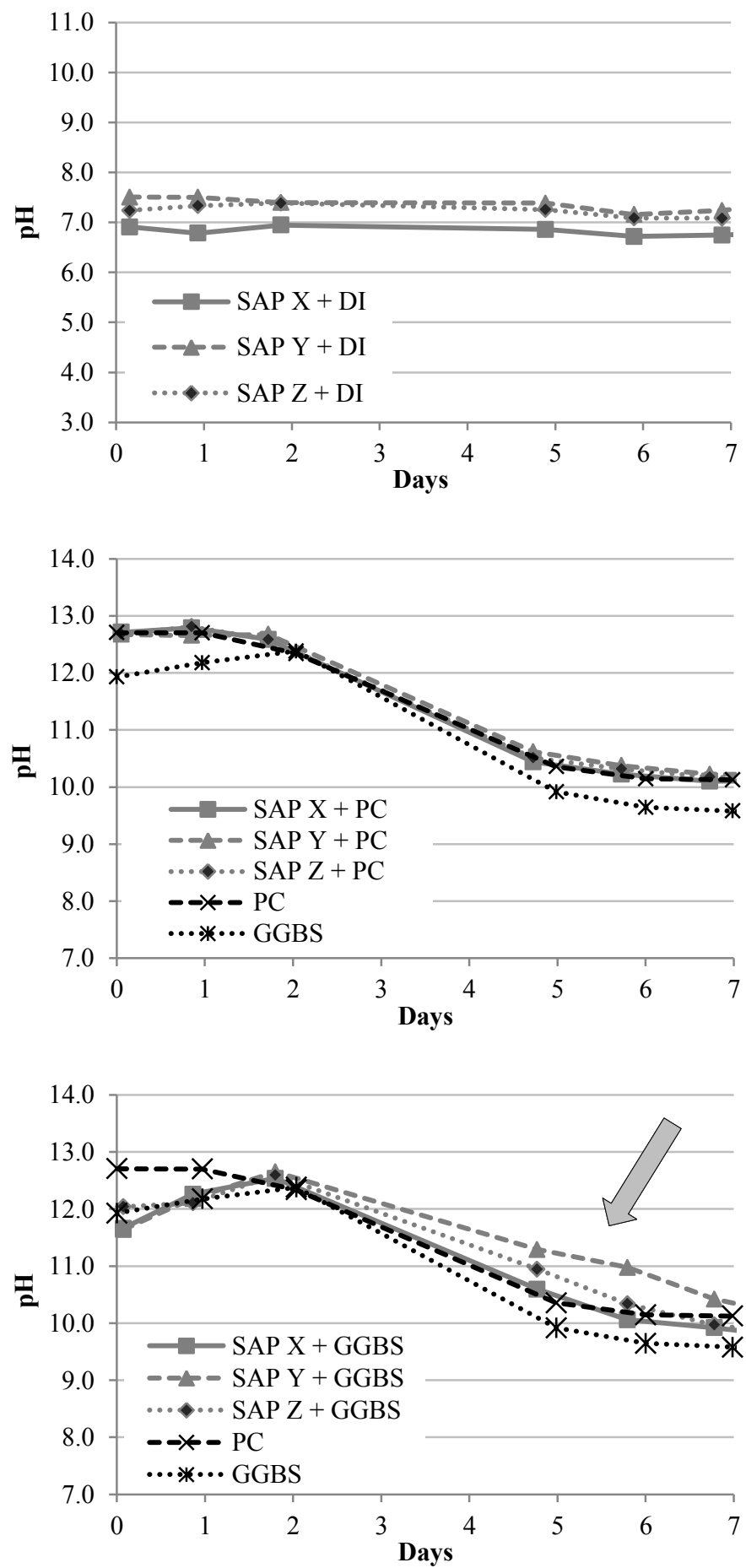

Fig. 3. $\mathrm{pH}$ analysis of SAP solutions in deionised water (DI), PC and GGBS filtrates 

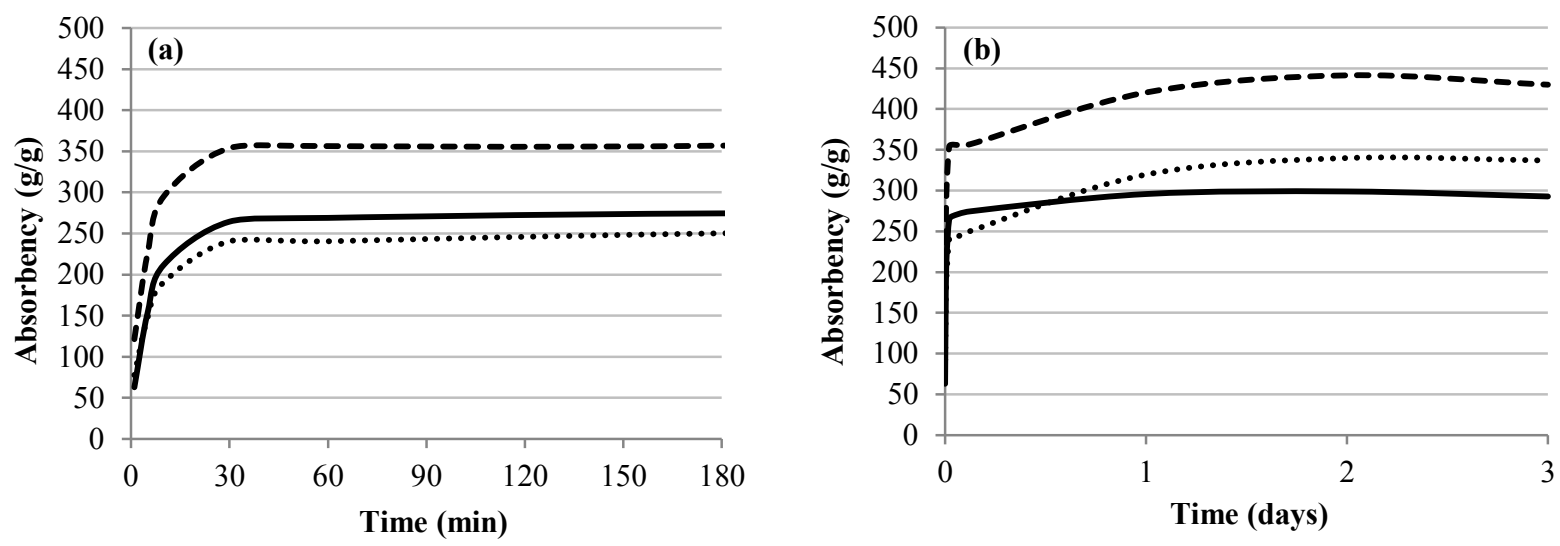

$\longrightarrow$ SAP X + DI - - SAP Y + DI $\cdots \cdots \cdot$ SAP Z + DI

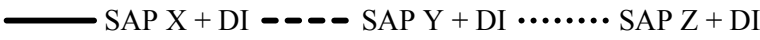

Fig. 4. Sorption behaviour of SAPs in DI water: (a) up to $180 \mathrm{~min}$; (b) up to 3 days 

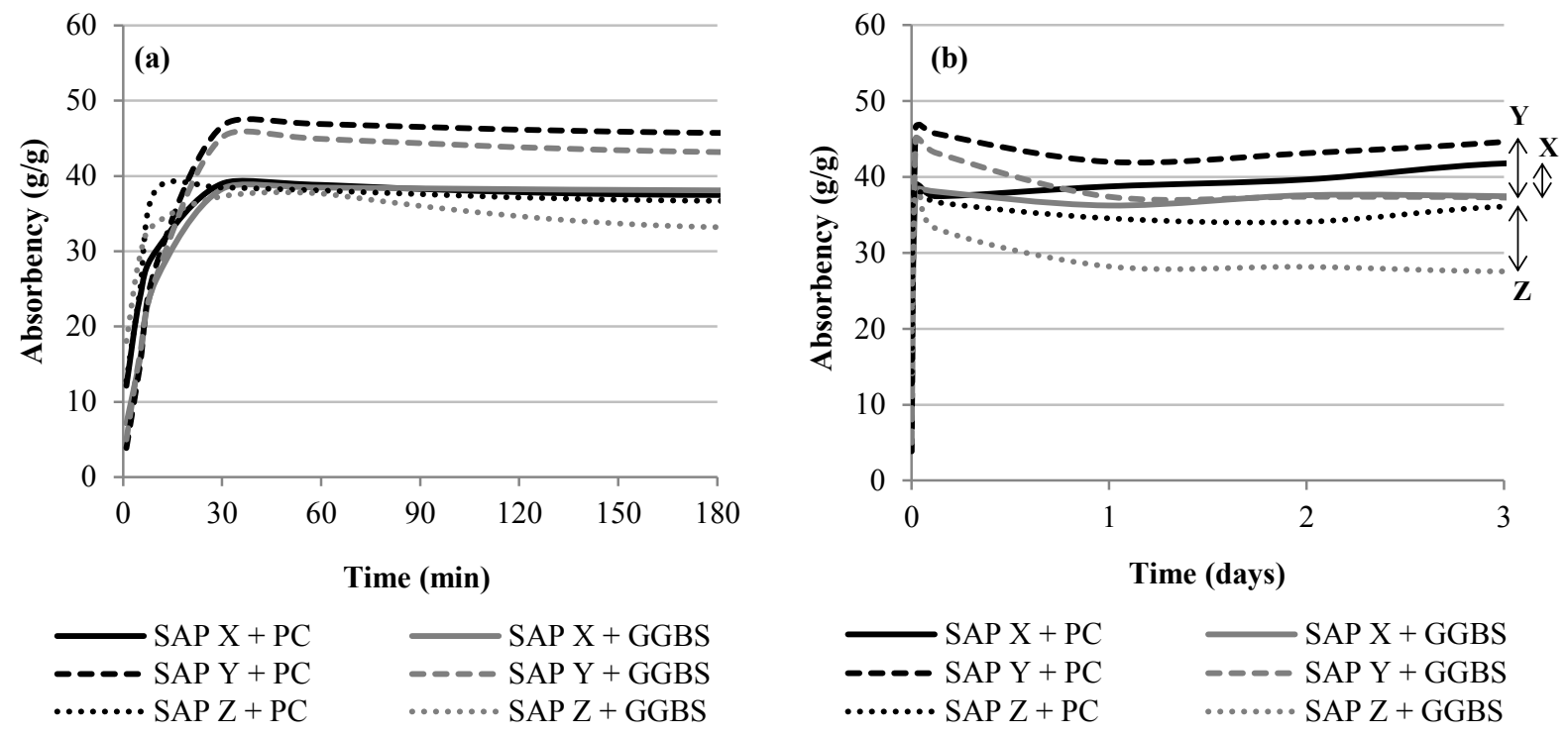

Fig. 5. Sorption behaviour of SAPs in cementitious solutions: (a) up to $180 \mathrm{~min}$; (b) right: up to 3 days. Arrows in graph (b) indicate the difference between absorbency in PC and GGBS systems for all SAPs 


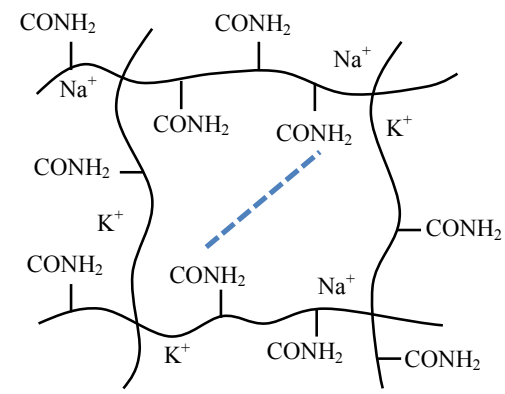

--- Hydrogen bonds in DI water

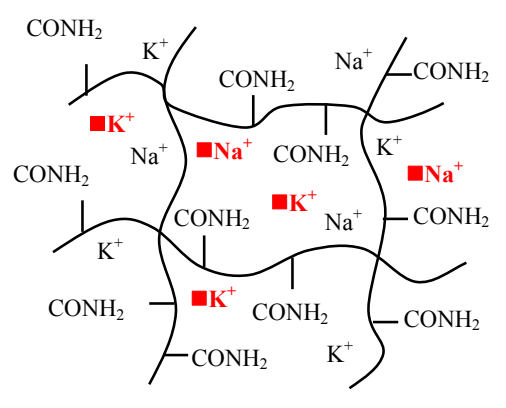

Excess of alkalis in PC solution

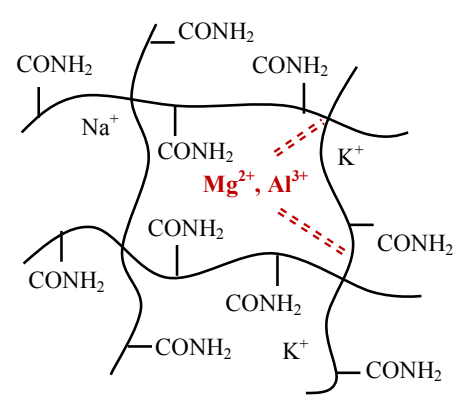

$==:$ Complexing bonds with GGBS solution

Fig. 6. Polyacrylamide structures and their modifications (adapted from Chu et al. 2008) 

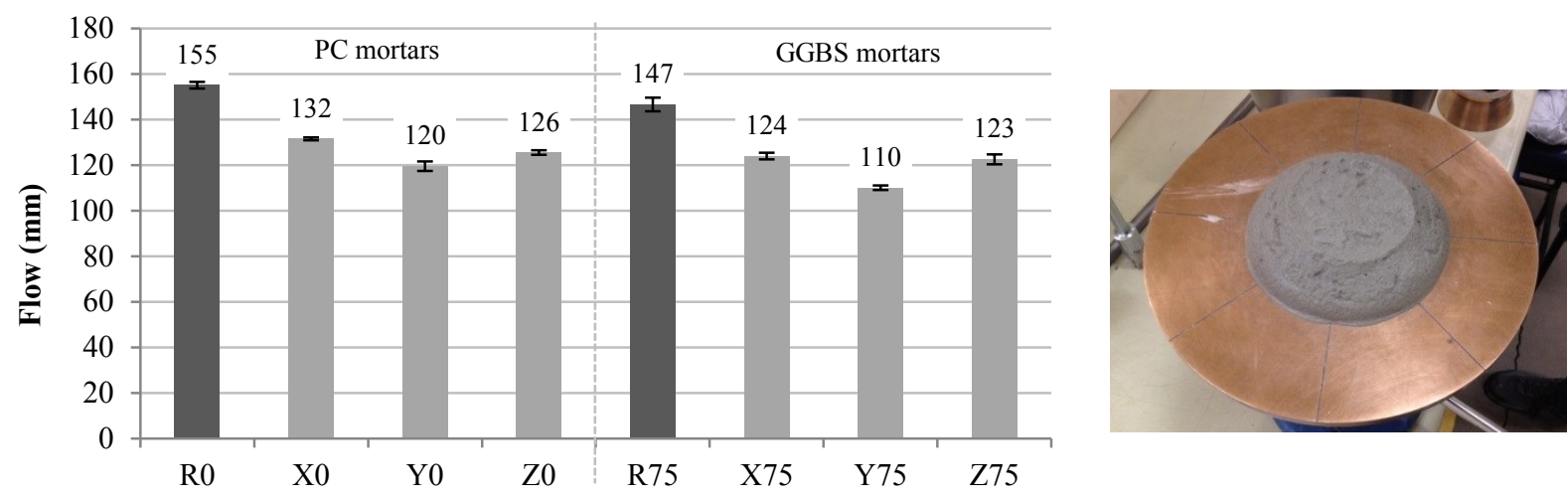

Fig. 7. Flow-table results of PC-GGBS mortars modified by SAPs 


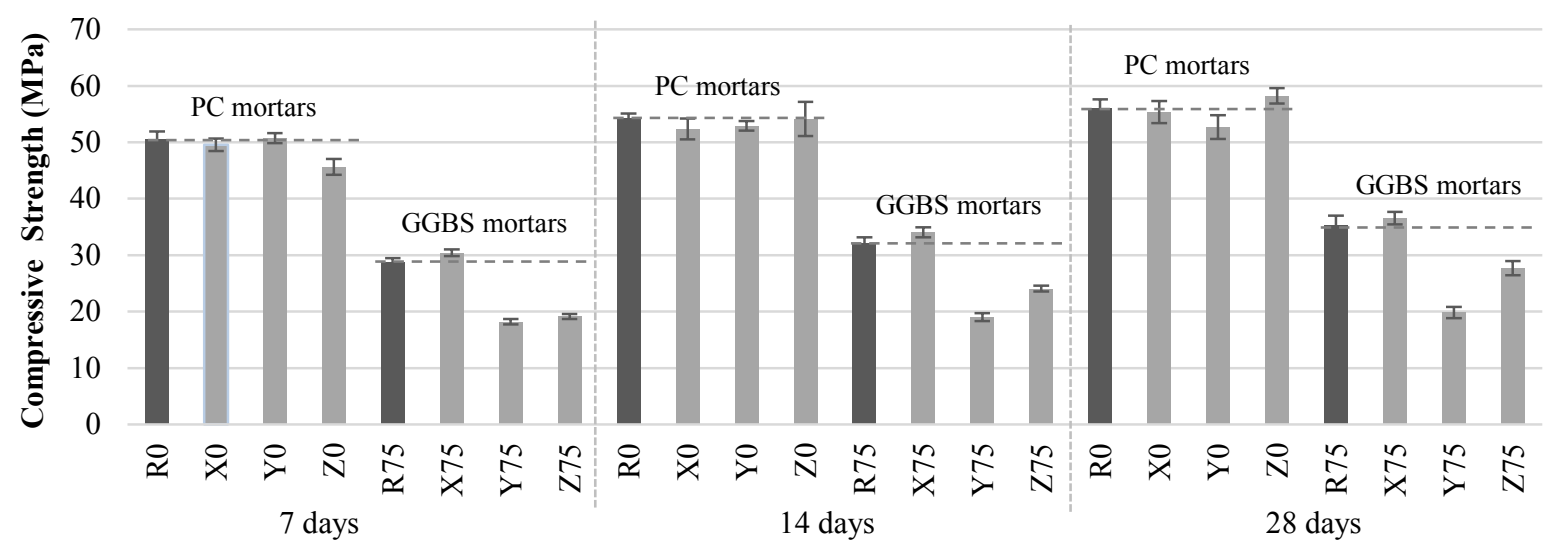

Fig. 8. Compressive strength results of PC-GGBS mortars modified by SAPs 

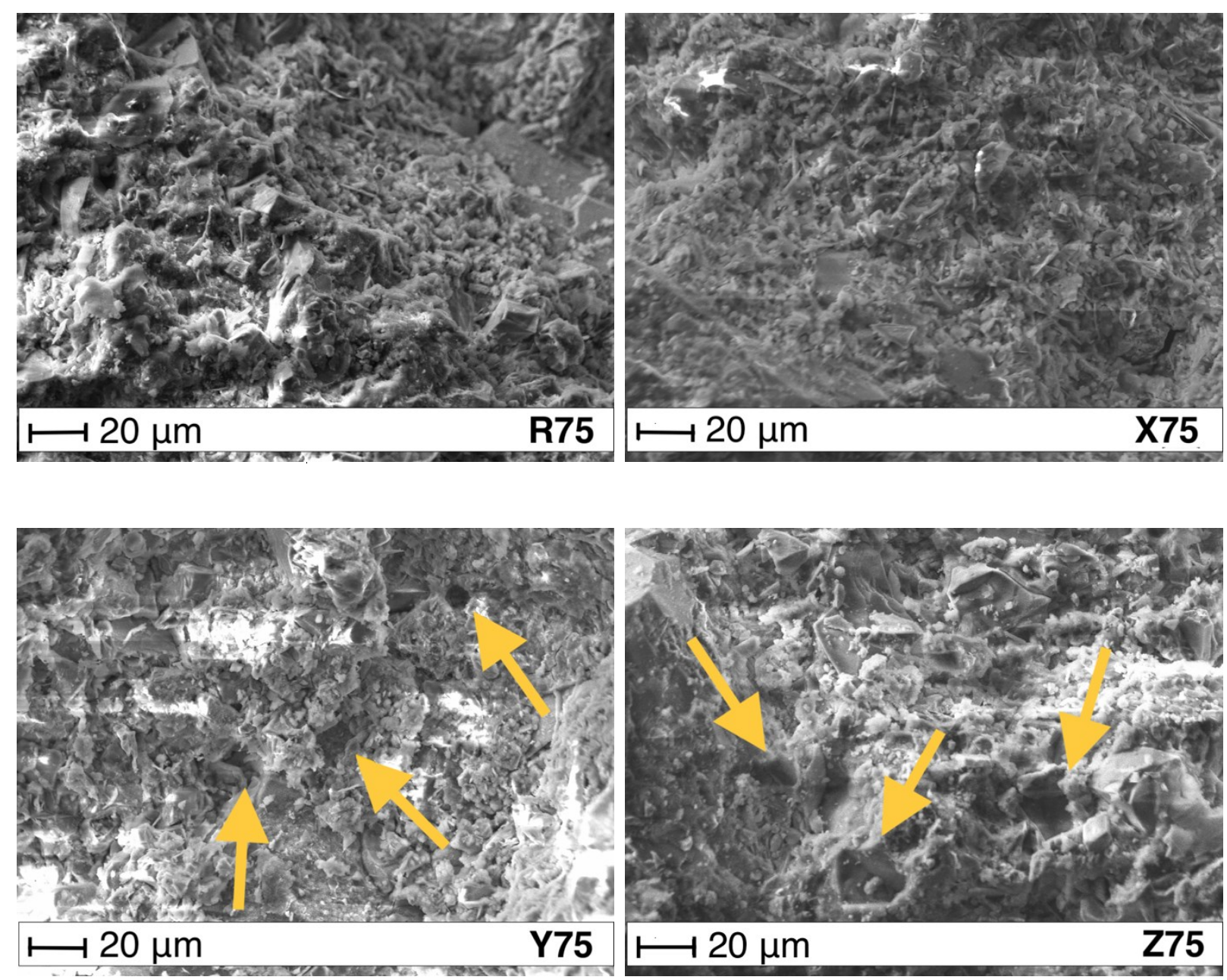

Fig. 9. SEM micrographs of GGBS mortars at 28 days (indication of larger pores in samples modified by SAP

Y and SAP Z) 


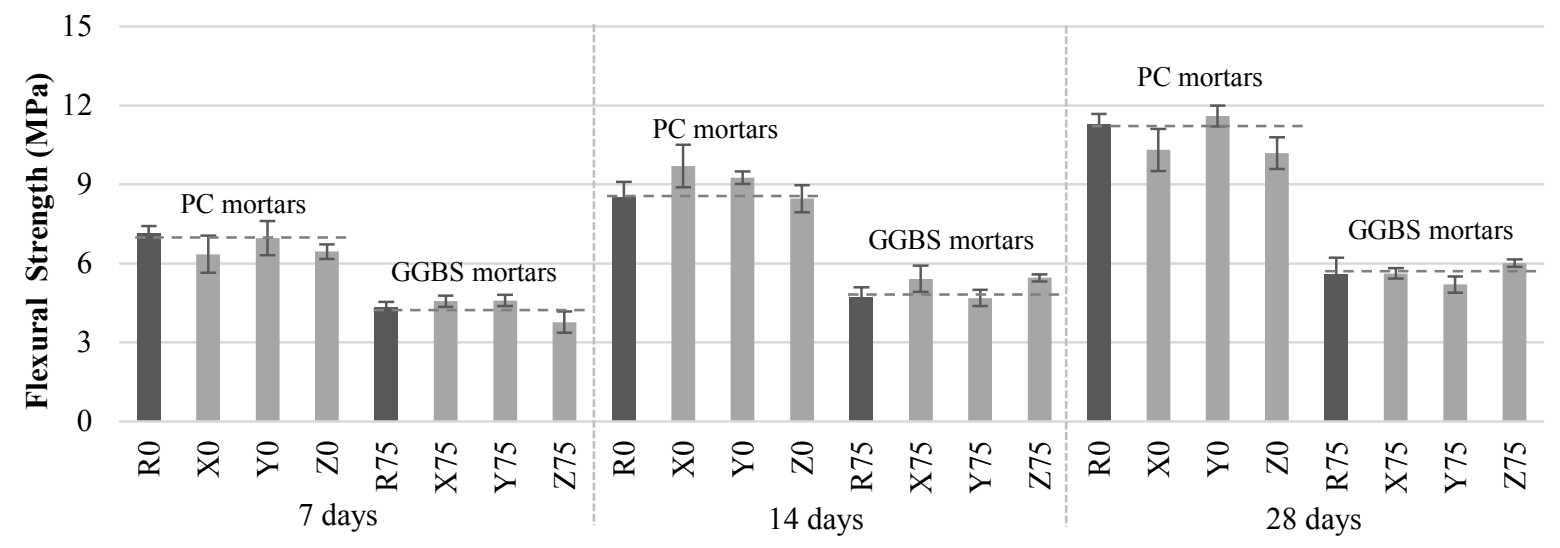

Fig. 10. Flexural strength results of PC-GGBS mortars modified by SAPs 